\title{
Deictic Verbs in Modern Linguistics
}

\author{
Chunrong Wang \\ School of Foreign Languages \\ Shanghai University of Political Science and Law \\ Shanghai, China
}

\begin{abstract}
Deictic verbs is a relatively small category of deixis. Studies on deictic verbs have so far focused on motion verbs such as come and go as well as their causative counterparts bring and take. Major findings include studies relating to deictic center, appropriateness conditions and perspective. This paper is intended to review representative works on deictic verbs in modern linguistics, and hopefully to propose new research suggestions on the basis of the limitations of the status quo.
\end{abstract}

Keywords-deictic verbs; motion verbs; deixis; modern linguistics

\section{INTRODUCTION}

Deixis is an important field in modern linguistics particularly in semantics and pragmatics. Deixis refers to the phenomenon wherein the meaning of certain words and phrases in an utterance requires contextual information. There are basically five categories of deixis, namely person, space, time, social and discourse deixis. Deictic verbs, also known as deictic motion verbs, refer to any verb that marks the direction in which an entity is moving such as come and go [1]. Strictly speaking, deictic verbs fall into the category of space deixis, and remain a relatively small research field compared with other types of deixis. Therefore they are worthy of being studied and explored.

This paper is intended to review previous studies on deictic verbs in modern linguistics. In the western academia, most studies have mainly focused on motion verbs come and go, together with other motion verbs such as leave, depart, bring and take. There have long been three major approaches to the semantics of deictic motion verbs. The first approach is based on the concept of deictic center. The second approach is to work out the appropriateness conditions for deictic motion verbs based on the notion of person, space and time. The third approach is the perspective through which the speaker views the motion that takes place. Reviewing these representative works will help us to have a clear view of the research status quo of deictic verbs, on the basis of which new research directions can be proposed.

\section{StUdies Relating TO DeICTIC CENTER}

Deictic center, a key notion in the study of deixis, is a reference point that a deictic expression is anchored to, and from which it points at some element in the world. Thus the interpretation of a deictic expression leads one to the relevant reference point. In the unmarked case, the prototypical deictic center is the spatial-temporal axis in the immediate context, namely the speaker's location at the time of the utterance, In what follows, we will review some representative works of deictic verbs come and go relating to the notion of deictic center.

\section{A. Talmy's Model}

It is observed that some motion verbs are deictic in the sense that they mark a direction in which an entity is moving and such movement is grounded on a spatialtemporal reference point, the deictic center. Therefore, the deictic center of any motion verbs will be understood to be the intersection of parts of the complex SOURCE-PATHGOAL schema, and the unmarked deictic center is the speaker and the speaker's location at the moment of utterance. For example, verbs like come, arrive, reach and bring inherently profile the goal of a movement towards the speaker whereas verbs like go, leave, depart and take inherently profile the source of a movement away from the speaker, and verbs like move, pass, travel inherently profile the path of a movement, which seems irrelevant to the location of the speaker.

Talmy is one of the early linguists who have proposed the deep semantic components of motion situation as FIGURE + MOTION + PATH + GROUND [2]. Decades later his reformulation of the framework adds the feature of deixis: deictic motion verbs are a kind of Path-conflating verb with a special choice of the Path and the Ground, and the deictic component of Path typically has only the two member notions "toward the speaker" and "in a direction other than toward the speaker" [3].

a) Go describes motion from the speaker or his proxy (the individual whose perspective the speaker takes).

b) Come describes motion toward the speaker or his proxy (the individual whose perspective the speaker takes).

Generally the unmarked deictic center is the speaker, but just as what Talmy has noticed, the deictic center can be shifted to some individual other than the speaker, the individual whose perspective the speaker takes. In the following examples, come refers to motion toward the addressee in (1) and John in (2).

(1) Can I come visit you? 

him.

(2) John was preparing a meal. Then, the cat came to

However, the deictic shift does not seem as simple as the above examples show; rather it is subject to various restrictions such as topicality and is sometimes language specific.

\section{B. Clark's Hypothesis}

The motion verbs come and go also have a large number of non-literal or idiomatic uses where they refer not just to motion but to change of state, e.g. come to one's senses, go $\mathrm{mad}$, etc. Clark extends this deictic analysis of come and go to idiomatic uses regarding change of state [4]. She claims that come and go, as well as their causative counterparts bring and take/send may be used in idioms to refer to change of state rather than to motion. In such idiomatic uses, go marks departure from normal states while the goal or destination of come, corresponding to deictic center, is regarded as some normal states of being, e.g. being sane and conscious (vs. non-consciousness), calm or equanimity (vs. frenzy, irascibility), wakefulness (vs. daydreaming), non-use of drugs (vs. drug use), normal functioning (vs. malfunctioning) and usual complection (vs. pallor or flush), etc.

Normal states always involve acceptable or expected behavior of some kind while non-normal ones do not, exemplified by some particular sentences as below:

(3) $\mathrm{He}$ went/*ame out like a light. [=became unconscious]

(4) He went/*came out of his mind. [=became mad]

(5) He came/*went round very slowly.

$$
\text { [=regained consciousness] }
$$

(6) They quickly came/*went back to their senses.

[=regained consciousness; took hold on reality again]

[note: The starred forms mark predicted non-occurrences]

Clark and other several linguists (e.g. Lakoff [5]; Binnick [6]) extend the idiomatic use of come and go to their agentive or causative counterparts bring and take/send. In other words, bring is viewed as CAUSE to come and take as CAUSE to go (along with) and send as CAUSE (to begin) to go. Thus following Clark's hypothesis, the agentive or causative of come would refer to entry into a normal state and that of $g o$ would refer to departure from a normal state.

(7) a. The drug sent Harry into a coma yesterday.

b.*The drug brought Harry into a coma yesterday.

(8) a. The lawyer brought Philip to his senses.

b.*The lawyer sent (took) Philip to his senses.

\section{Malsch and Lant's Model}

On the basis of Clark's hypothesis of normal states, Malsch and Lant (1977) go further to study deictic motion verbs come and go, and provide examples that Clark's hypothesis fails to account for [7].

(9) a. Betty's sweater came unraveled.

b. *Betty's sweater went unraveled.

(10) a. Alfred's model of the Titanic came unglued.

b. *Alfred's model of the Titanic went unglued.

Malsch and Lant are skeptical of Clark's account for the way come and go are used to describe changes of states. In (9) and (10) it seems the acceptability of come and go is just reversed as opposed to Clark's designation of normal state. They argue that if we followed Clark that come indicates a change of state from being abnormal to the normal one, then we would assume that objects in their disassembled, nonfunctioning or broken state would have to be considered normal. Thus they are doubtful whether deictic center has any relevance to the normal state.

Malsch and Lant's explanation for such different preference for come and go is that the objects in (9) and (10) are not viewed holistically in that the fabricated objects and the change of state specifically involve reference to the means of fabrication or to components of the object. Moreover, they further argue that such distinction between a fragmented and holistic view of objects in change of state also holds in the description of certain events involving animate beings and their body parts such as (11) - (12).

(11) a. Martin came unglued after his divorce.

b. *Martin went unglued after his divorce.

(12) a. Lizzie came apart at the seams when she heard the news.

b. *Lizzie went apart at the seams when she heard the news.

So far we have reviewed some representative studies on deictic motion verbs relating to deictic center, showing that deictic center is an important notion that should always catch our attention in investigating any deictic terms and expressions.

\section{STUDIES RELATING TO APPROPRIATENESS CONDITIONS}

The deictic phenomenon of come and go is a much more complex phenomenon. In this section we will review some representative studies on appropriateness conditions of come and $g o$, another important arena of studying deictic motion verbs.

\section{A. Fillmore's model}

Charles Fillmore analyses the appropriateness conditions of come and go in terms of person, place and time. The relevant parameters of person are: speaker and addressee; of place, the goal of motion; and of time, coding time and reference time. Coding time is defined by Fillmore as the time of the speech or communication act, and reference time as "the point or period that is the temporal focus (...) for the 
event (...) described in the clause" [8]. Using these parameters, Fillmore formulates a set of appropriateness conditions for the use of come and $g o$ in English, as illustrated below in Table I.

TABLE I. APPROPRIATENESS CONDITIONS FOR THE USE OF COME AND Go IN ENGLISH

\begin{tabular}{|l|l|l|}
\hline \multicolumn{1}{|c|}{ Goal of movement } & come & go \\
\hline 1. speaker's location at coding time & $\boldsymbol{V}$ & \\
\hline 2. speaker's location at reference time & $\boldsymbol{V}$ & $\boldsymbol{V}$ \\
\hline 3. addressee's location at coding time & $\boldsymbol{V}$ & $\boldsymbol{V}$ \\
\hline 4. addressee's location at reference time & $\boldsymbol{V}$ & $\boldsymbol{V}$ \\
\hline 5. any other location & & $\boldsymbol{V}$ \\
\hline
\end{tabular}

As emerges from the table, motion towards the speaker at coding time must always be expressed by come, motion towards the speaker at reference time or towards the addressee at coding time or reference time may be expressed by the use of come or go and motion towards any location excluding that specified in the previous conditions must be expressed by go.

Fillmore also mentions three further factors conditioning the use of come and go: the home-base condition, the comitative condition and a central character of a narrative. Under these appropriateness conditions both come and go are acceptable. It is illustrated in "Table II".

TABLE II. HOME BASE, COMITATIVE AND CENTRAL CHARACTER OF A NARRATIVE CONDITION

\begin{tabular}{|l|l|l|}
\hline \multicolumn{1}{|c|}{ Goal of movement } & come & go \\
\hline 6. speaker's home base & $\boldsymbol{V}$ & $\boldsymbol{V}$ \\
\hline 7. addressee's home base & $\boldsymbol{V}$ & $\boldsymbol{V}$ \\
\hline 8. speaker in comitative contexts & $\boldsymbol{V}$ & $\boldsymbol{V}$ \\
\hline 9. addressee in comitative contexts & $\boldsymbol{V}$ & $\boldsymbol{V}$ \\
\hline 10. central character of a narrative & $\boldsymbol{V}$ & $\boldsymbol{V}$ \\
\hline
\end{tabular}

\section{B. Oshima's RP Model}

Admittedly, Talmy's and Fillmore's approaches have been quite influential in the literature and can explain a wide range of data, but they fall short in the interpretation in the following sentences [9].

(13) Can I \{??go/come $\}$ visit you?

(14) Will you $\left\{{ }^{*} \mathrm{go} / \mathrm{come}\right\}$ visit me?

It seems there exists an asymmetry between come and go that come is preferred to go. If it is possible for the deictic center to be shifted from the speaker to the addressee as proposed by Talmy and Fillmore, then why go in (13) is accepted but blocked in (14)?

In light of the above-mentioned problems Oshima proposes that GO/COME refer to a contextually provided set of individuals, which he calls RP (Reference Point), rather than to a specific individual that serves as the deictic center. Semantically, an RP can be understood as part (a coordinate) of the context of utterance in the Kaplanian sense. Thus deictic verbs can be treated as kinds of indexicals, on a par with I, here, now, etc.
The pragmatic meanings of come and go in Oshima's analysis can be briefly formulated as follows:

a. Go requires that no member of the RP be at the goal at the utterance time.

b. Come requires that (i) there be some member of the RP at the goal at the utterance time or at the event time, or (ii) the goal be the home base of a member of the RP at the event time.

Cross-linguistic differences are subject to different sets of person-based restrictions regarding the selection of members of the RP. Take English for example:

a. The speaker is always a member of the RP.

b. In many situations, it is preferred for the addressee to be a member of the RP as well.

c. A non-SAP (speech-act participant) (e.g. third person) entity can be chosen as a member of the RP if it is discourse-salient, i.e. when the speaker or the addressee is the theme (moving entity).

Thus, in English, typical RP $=\{$ the speaker, the addressee $\}$; marginal $\mathrm{RP}=\{$ the speaker, the addressee, a non-SAP1, a non-SAP2, a non SAP3... \}. Besides, go refers to the utterance time ONLY, while come refers to the utterance time, the event time, and the RP members' home bases.

The set-based analysis can thus make correct prediction regarding the asymmetry between come and go illustrated in (13) and (14) above, and the preference for come in a situation where the addressee is at the goal.

\section{Barlew's Model}

Deictic motion verbs denote motion along a path to a location of a specific individual, typically a speech-act participant. Thus Barlew uses 'anchoring' to refer to the motion and 'anchor' to refer to the relevant individual [10]. The use of come is acceptable if the destination of the motion path is anchor's current location, illustrated in the following example.

(15) [Context: Ann is in Cleveland, OH, and Beth is in New York. They are talking on the phone. Ann says to Beth Where is John these days? Beth answers:]

a. John is in Chicago. However, he is coming to New York tomorrow.

b. John is in Chicago. However, he is coming to Cleveland tomorrow.

c. *John is in Chicago. However, he is coming to Denver tomorrow.

The presence of the speaker and the addressee at the destination makes (a) and (b) acceptable. (c) shows that come cannot be used to describe John's motion to a destination where there is no anchor. 
Following Fillmore's person-based analysis, Barlew's anchoring implication of deictic motion verb come can be formulated in the following four aspects:

a. The anchor is located at the destination of the motion event at utterance time.

b. The anchor is at the destination at (motion) event time.

c. The destination is anchor's home base.

$\mathrm{d}$. The motion is in the company of the anchor.

The following example is to exemplify $b-d$ :

(16) [Context: Ann and Beth are in Gambier, Ohio. Ann says:]

a. I went to see Prof. Smith in Lupton Hall earlier today. While I was there, John came to Lupton to meet with Prof. Rogers. (Ann at the event time)

b. John came \{to my house/to Gambier\} earlier today, but I wasn't home. (Ann's home base)

c. John came to North Carolina with me last month. (in the company of Ann)

The sentence c. is a good example to show how classical approach falls short in the explanation of the use of come. Even Oshima's RP analysis cannot account for it satisfactorily, because though the speaker is the moving entity and John can be treated as a member of the RP, he is not at the goal at the event time.

To briefly sum up, the previous researches on the appropriateness conditions of come and go mainly deal with sematic rules so as to avoid the production of inappropriate sentences containing these deictic motion verbs.

\section{StUdies Relating TO PERSPECTIVE}

After reviewing the first and second approaches to the studies of deictic motion verbs, we shall now come to the third approach, namely studies on the perspective through which the speaker views the motion that takes place.

\section{A. Perspective Taking}

Fillmore further explored this deictic feature of motion verbs by pointing out that the possible spatial relations that deictic verbs determine between the speaker and the addressee of an utterance, or between the speaker and the events described in his utterance [8]. Thus the position of an observer, or the location of some reference point is often indexed through manipulation of the deictic verbs come and go.

(17) The door of Harry's lunchroom opened and two men came in/went in [11].

Not only are the source and goal of came and went dependent on the context of situation, but also come is used to signal motion directed toward the deictic center (i.e. the observer) while go signals motion directed away from the observer. Thus the verb come puts the speaker inside the diner, if we were going to film this scene, the camera would need to be located inside the diner. But the verb go puts the speaker outside the diner. A camera filming the scene would have to be located out on the street. Fillmore's observation leads us to find a interesting feature of come and go that they encode a perspective from which the speaker takes when viewing the action described in the utterance.

\section{B. Perspective Shifting}

Brown explores the deictic feature of depart and leave in English and proposes that verbs of motion, used deictically, can be construed as offering the speaker the opportunity of expressing at least three different perspectives or points of view on the action being described in the utterance [12].

Brown cites a sentence from Colins CoBuild Dictionary: The rescue ship departed from the area as soon as possible. (left or went away could be substituted for departed from) This example may be construed in at least four different ways:

a. as objectively reporting the departure of the rescue ship from the danger area, with the reporter, a nonparticipant, adopting no particular point of view: a nondeictic use.

b. as reporting the departure of the rescue ship from the point of view of a person on the putative sinking ship (the source), seeing the last hope of rescue fade away. In this case, the speaker stays on stage and witnesses the departure for an unspecified goal. This is a typical deictic use of ' $X$ departing from me' (though pragmatically and stylistically a fairly implausible construal in this case unless one assumes a miraculous last-minute rescue by, say, helicopter, and that this is the abandoned person putting in a later report).

c. as reporting the departure of the rescue ship from the point of view of someone who participated in the departure. The speaker looked back at the sinking ship from the rescue ship, which was departing from the sinking ship as quickly as possible. This takes a different deictic view from that in b., and might be summarized as 'me departing from X'.

d. as reporting the departure of the rescue ship from the point of view of someone participating in the departure who now has a new lease of life and, by implication, a lively interest in the new destination. The speaker in this case turns his back on the sinking ship and looks towards the approaching shore. This is a deictic use with the sense of 'me departing from $\mathrm{X}$ to $\mathrm{Y}$ ', where $\mathrm{Y}$ is regarded as the goal, the place of primary interest.

\section{Evaluative Viewpoints}

Besides the idiomatic uses of come and go that designate normal state previously reviewed in section II, there also exist certain other idiomatic uses of come and go that take non-literal meanings of what Clark calls evaluative viewpoints [4]. In such uses, the destination of come corresponds to some state which the speaker implicitly situates himself in and which is usually regarded to have general approval. Go simply defines a destination as 'somewhere else' in relation to the speaker, which makes go detached from general approval in evaluative statements. 
Therefore, evaluative come carries consistently with it a positive connotation, while evaluative go in an otherwise identical utterance carries a neutral or occasionally negative connotation.

\section{(18) Look at all he came through}

(19) Look at all he went through.

The positive connotation implies by the speaker in (18) may show his approval or support for what the protagonist has achieved. However, no such approval is implied in (19) in which the speaker is quite neutral about the protagonist's destination.

The use of come also suggests that the speaker's positive involvement in the described event, showing his implicit support or favor or interest in it. But the use of go doesn't imply any such positive involvement.

(20) The tomatoes are coming along nicely this year.

(21) The tomatoes are going along nicely this year.

The come in (20) indicates that the sentence might be uttered by the grower himself or by someone who favors growing tomatoes. Such persons are less likely to produce (21) in that no positive favor is implied but a negative detachment from the issue in question. Therefore, (21) seems more likely to be uttered by a neutral observer who cares less about tomato growing.

The evaluative point discussed so far is also workable for the causative forms bring and take/send.

(22) The cockroach invasion brought Alan down with hysterics.

(23) The cockroach invasion sent Alan down with hysterics.

In summary, the evaluative points, i.e. positive with come, non-positive with go, provide us with yet another insight into the use of deixis. Thus we can see that deictic motion verbs can be approached from different angles.

\section{SUGGESTIONS FOR FUTURE RESEARCH}

So far we have reviewed major works on deictic verbs in English, and it is time to propose some suggestions for future research on the basis of the research status quo. In what follows, three aspects of suggestions, together with some research questions, are to be offered hopefully to shed light on the future research directions.

Firstly, the notion of deictic verbs needs to be delimitated (or broadened perhaps) so as to include nonmotion verbs. It is tradition that deictic verbs and deictic motion verbs are changed interchangeably. Yet such terminology is not clearly demarcated. Generally speaking, verbs can be classified into motion verbs and non-motion verbs, the latter of which might include action verbs, modal verbs, stative verbs, etc. One curious question is whether motion verbs are the only type that is deictic? Naturally motion verbs deal with direction and change of state, which is closely related to space deixis. This explains, to a large extent, western linguists' strong interest in them. However, non-motion verbs can also be deictic in that the understanding of their meanings might require contextual parameters/features. For instance, Alam stuides benefactive deixis regarding the Japanese verbs of giving, kureru and yaru [13]. She argues if deixis refers to the egocentric aspect of language with which a human being establishes a relation between what may be generally called his 'ego' and the 'nonego', kureru and yaru are deictic verbs as come and go are. More recently, Wang studies deictic action verbs in English by exploring certain action verbs whose meanings requires contextual features in the immediate context of situation, social context and cultural context [14]. Wang explores for the first time non-motion verbs (i.e. action verbs) in English and analyses their sensitivity to contextual parameters in natural American utterances. These findings have marked the frontier research direction that deictic verbs are not confined to motion verbs.

Secondly, the research scope of deictic motion verbs needs to be expanded in that they should be approached in a multi-leveled context of utterances. Traditional studies focus mostly on the semantic variables or parameters in the spatial-temporal dimension (or the immediate context) of the utterances in which they occur (e.g. motion direction, time reference, perspective, appropriateness conditions, etc.) Unfortunately few studies on deictic motion verbs in English have been approached beyond the immediate context. As we all know, any utterance must take place in a spatial-temporal setting involving the place and time of the occurrence of utterances. But at the same time some (if not all) utterances make up the major part of interpersonal communication between speech participants. In this case, the social identities or status of speech participants constitute the social contextual parameters that might influence the use of motion verbs. For instance, Ochs observes the deictic motion verbs sau (come) and alu (go) in West Samoan society [15]. She finds out that imperatives with sau tend to be directed to lower-ranking persons or to peers, which reflects the fact that within the household it is high-ranking persons (i.e. adults and sibling caregivers) who generally issue such imperatives. From this perspective, it seems the verb sau pragmatically presupposes deictic elements in Western Samoan community in that it may make indexical reference to the social status of speakers, addressees, overhearers and referents. McClain examines the paradigm of deictic motion verbs and deictic directional suffixes in the P'urhepecha language [16]. He hopes to shed light on cultural models of motion as embedded in the grammatical structures that make up local discourses of P'urhepecha speakers. These studies are groundbreaking and quite illuminating, though they target at non-English languages. This indicates that deixis is a language-specific phenomenon. Deictic motion verbs or directionals can be approached in socio-cultural dimension, but this might or might not be applicable to the English counterparts. Perhaps English deictic motion verbs can be approached but in a specific way? Or perhaps can other types of verbs that are deictic be approached in this way? These interesting questions deserve our attention and further exploration. 
Thirdly, the category of action verbs deserves our special attention and effort to investigate whether some of them can be deictic in natural language utterances. As aforementioned, motion verbs can be deictic because they are related to spatial direction, a subcategory of space deixis. However, Levinson has long noticed the pervasiveness of deixis in natural language and its boundary problem. In other words, deixis in natural language is a much more pervasive phenomenon than we have thought. He says that most sentences in natural language are deictically anchored, for they may contain some linguistic expressions that encode context-sensitive contextual parameters of utterances [17]. Action verbs describe people's actions, and what they do are, to a large extent, subject to the constraints of social conventions and cultural norms, beliefs and values. From this perspective, it seems there is a lot to explore.

On the one hand, honorific action verbs are used as a sign of deference, especially in relation to someone who is of higher social status. These action verbs are socially deictic because they encode the social identities or status of speech participants, and they are quite prevalent in East Asian languages like Chinese, Japanese, Korean, etc. English that is commonly claimed to be relatively poor in honorific system (e.g. honorific verbs) probably due to the value of equality prevalent among its native speakers. Considering the morphological and lexical characteristics of English, it is clear that honorific action verbs are not realized at the morphological level, because the inflection or conjugation in contemporary English does not reflect any honorific distinction which is instead represented at the lexical level. For instance, action verbs such as consult, welcome, beg and please do indicate the undertone of politeness and respect in social interaction. Besides single verbs, some phrasal verbs or grammatical structures can also achieve the same effect, such as would you please ..., I'd appreciated if you could ..., etc. These are only a few examples, and a systematic investigation could be our future research.

On the other hand, culturally deictic action verbs can be a new and promising research domain. Cultural deixis is a new category of deixis following the five tradition categories. In more recent years some scholars, such as Ochs [18], Brøgger [19], Robles [20], He [21] and Wang [22], etc. have noticed the phenomenon of cultural deixis in natural language. These works can be referred to for a detailed description of cultural deixis. Thus if we follow the theoretical framework of cultural deixis, culturally deictic action verbs can be understood as those action verbs that encode or grammaticalize specific cultural norms, beliefs, values and other cultural assumptions in mainstream culture. So when these action verbs are uttered in daily communication, the relevant cultural information (cultural meanings, metaphors, connotations, historical significance, etc.) can be indexed or associated to. However, one of the challenges is the scope of cultural context that is broad and complex. Which action verbs are culturally deictic and which are not? The cultural indexicality is lexically encoded or occurs in the course of the verbal interaction? These questions deserve our special attention and dedicated investigation.

\section{CONCLUSION}

In this paper, we have done a fairly comprehensive review of the studies on deictic verbs in modern linguistics. By reviewing representation works on deictic verbs, we have categorized thee major approaches to the semantics of deictic motion verbs come and go as well as their causative counterparts. What these approaches have in common is that deictic motion verbs are studied in spatial-temporal dimension of the immediate context of situation, be it physical or metaphorical. The research scope of deictic verbs is somewhat narrow and limited. On the other hand, the context in which deictic verbs are studied is just confined to the physical context (spatial-temporal setting), and social and cultural context seem to be ignored. On the basis of the research status quo and limitations of the studies on deictic verbs in English, this paper has finally proposed three future research directions such as a broader delimitation of the notion of deictic verbs, the consideration of multi-leveled context, especially the involvement of social and cultural context in the study of deictic motion verbs, and the new research domain of deictic action verbs. In doing so, we hope that attention can be drawn to this special category of deixis in linguistic circle and studies with new research methods or directions can be conducted.

\section{REFERENCES}

[1] Y. Huang, The Oxford Dictionary of Pragmatics. Oxford: Oxford University Press, 2012, p.86.

[2] L. Talmy, "Semantics and syntax of motion," in Syntax and Semantics 4, J.P. Kimball, Ed. New York: Academic Press, 1975, pp.181-238.

[3] L. Talmy, Towards a Cognitive Semantics: Typology and Process in Concept Structuring. Vol.2. Cambridge, London: The MIT Press, 2000, p.56.

[4] E. Clark, "Normal states and evaluative points," Language, 50(2), 1974, pp.316-332.

[5] G. Lakoff, "Linguistics and natural logic," Synthèse 22, 1970, pp.151271.

[6] R. Binnick, "Bring and come," Linguistic Inquiry, 2, 1971, pp.260265.

[7] D. Malsch and K. Lant, "On 'Normal State' deixis," Linguistic Inquiry, 8(4), 1977, pp.744-746.

[8] C. Fillmore, "Toward a theory of deixis," University of Hawaii working papers in linguistics, 3, 1971, pp.219-242.

[9] D. Oshima, "Go and come revisited: what serves as a reference point?" Proceedings of the 32nd Berkeley Linguistics Society, 2006.

[10] J. Barlew, "Perspectives in discourse: the case of the motion verb come," accessible http://semanticsarchive.net/Archive/Tg2NzQ1N/barlew_pe rspectives.pdf, 2016.

[11] C. Fillmore, "Pragmatics and the description of discourse," in Pragmatik II, S. Schmidt, Ed. Munich: Wilhelm Fink Verlag, 1976, pp.84-104.

[12] G. Brown, "Point of view and the place to be: the English verb depart," in Le Départ: variations sur un thème, C. Majolas-Leblond, Ed. Lyon University Press, 2000, pp.49-61.

[13] Y.S. Alam, "Deixis and Implicit Argument of Japanese Verbs of Giving," in Papers from the 4th International Meeting of the 
Southeast Asian Linguistics Society, U. Warotamasikkhadit and T. Panakul, Eds. 1998, pp. 213-228.

[14] C.R. Wang, Deictic Action Verbs in Utterance Understanding. Ph.D. Thesis. East China Normal University, 2017.

[15] E. Ochs, Culture and language development: language acquisition and language socialization in a Samoan village. Cambridge: Cambridge University Press, 1988.

[16] S. McClain, "Motion deixis, home base and social indexicality among P'urhepecha," UC San Diego Electronic Theses and Dissertation. Permalink at http://escholarship.org/uc/item/85r367r3.

[17] S. Levinson, "Deixis," in Concise Encyclopedia of Philosophy of Language, P. Lamarque, Ed. Oxford: Elsevier, 1997, pp.214-219.

[18] E. Ochs, "Indexicality and socialization," in Cultural psychology: Essays on comparative human development, J.W. Stigler, R.A. Shweder and G. Herdt, Eds. Cambridge: Cambridge University Press, 1990, pp.287-308

[19] F. Brøgger, Culture, Language, Text: Culture Studies within the Study of English as a Foreign Language. Oslo, Norway: Scandinavian University Press, 1992.

[20] J. Robles, "Culture in conversation," in Inter/cultural Communication: Representation and Construction of Culture in Everyday Interaction, A. Kurylo, Ed. Thousand Oaks, CA: Sage, 2012, pp.89-114.

[21] G. He, "Interpreting the cultural deictic modes: instantiated by contemporary American English utterances," Journal of Zhejiang University (Humanities and Social Sciences), Vol.44, No.8, 2014, pp.174-184.

[22] C.R. Wang, "Theory of cultural deixis: an example of American English," Journal of Shanghai University (Social Sciences), Vol.35, No.5, 2018, in press. 